\title{
The Influence of Frailty on Infant and Child Mortality in Rural Nigeria
}

\author{
Anthony I. Wegbom ${ }^{1, *}$, Joshua O. Akinyemi ${ }^{2}$, Clement K. Edet ${ }^{3}$ \\ ${ }^{1}$ Department of Mathematics/Statistics, Port Harcourt Polytechnic, Port Harcourt, Nigeria \\ ${ }^{2}$ Department of Epidemiology and Medical Statistics, Faculty of Public Health, College of Medicine, \\ University of Ibadan, Ibadan, Nigeria \\ ${ }^{3}$ Department of Planning, Research and Statistics, Rivers State Primary Health Care Management Board, Port Harcourt, Nigeria \\ *Corresponding author: wegbomanthony@gmail.com
}

\begin{abstract}
Background: Infant and child mortality remains a major public health challenge in Nigeria and other parts of the developing world with rural areas sharing the largest burden which of course have devastating effects on concerned mothers and the population at large. This study was conducted to determine the effect of frailty and which of infant or child mortality is most affected by unobserved heterogeneity in Rural Nigeria. Methods: Data from 2013 Nigeria Demographic and Health Survey were analyzed. Weibull frailty models were fitted. The frailty effects, Hazard ratio (HR) and its 95\% confidence interval (CI) were estimated. Results: The frailty value in infant and child mortality are 51.8 and 56.5 percent respectively, which means that the covariates in infant and child models explained 48.2 percent and 43.5 percent family variation in infant and child deaths in rural Nigeria. Conclusion: Child mortality is more affected by unobserved heterogeneity than infant mortality in rural Nigeria.
\end{abstract}

Keywords: mortality determinants, Frailty, Under-five mortality, Rural Nigeria, Weibull Model

Cite This Article: Wegbom A.I., Akinyemi J.O., and Edet C.K., "The Influence of Frailty on Infant and Child Mortality in Rural Nigeria.” American Journal of Public Health Research, vol. 6, no. 1 (2018): 21-25. doi: 10.12691/ajphr-6-1-5.

\section{Introduction}

It is a known fact that infant and child mortality remains a major public health issue in Nigeria and other low and middle income countries with rural areas sharing the largest burden which of course have devastating effects on concerned mothers and the population at large. Child mortality reduction has become a common agenda of public health and international agencies [1]. It is also an important indicator of living conditions of a country and children's well-being. According to UNICEF reports, approximately 18,000 children under-five years die every day with huge variation across region and countries as well as urban and rural areas [2].

Children in rural areas are faced with higher mortality than their urban counterparts [3]. Higher rates in infant mortality in rural areas are derived from both observed and unobserved disadvantages in household characteristics and these explain for two-thirds of the differentials, less than one-quarter of the differentials is explained by Community characteristics, with about two-thirds coming from community unobserved heterogeneity while the most contributing factors are the environmental factors (such as electricity, a safe source of drinking water, and quality of housing materials) [4]. There are significant spatial differences in infant mortality rates and under-five mortality rates among the Nigerian six geo-political regions and by rural urban residence [5]. Also, a study in rural Nigeria shows that access to good health facilities and antenatal care, birth interval, maternal education, mother source of income, where babes are delivered and mothers age at birth are factors responsible for high rate of child mortality in rural Nigeria [6].

Because of the challenge infant and child mortality pose to public health in Nigeria and other developing countries, researchers have made considerable efforts to understand factors motivating the phenomenon. Many studies have shown that infants and child mortality rates vary by socio-economic and bio-demographic characteristics [7-13].

In Nigeria, according to 2013 NDHS report, Infant mortality is 43 percent higher in rural areas (i.e. 86 deaths per 1,000 live births) than in urban areas (60 deaths per 1,000 live births) and child mortality is 89 deaths per 1,000 live births in the rural areas as against 42 deaths per 1,000 live births in urban areas [14]. Data from a different environment indicate that the incidence of death in children are not randomly distributed families but, rather, that there is a positive association of sibling deaths $[9,15]$. A natural explanation of this would be that families in which child deaths are concentrated share some environmental or genetic risk factors that predispose their children to higher risks of death. These associations with infant and child mortality even after accounting for different observed factors of mortality in rural areas have been attributed to unobserved heterogeneity (such as genetic, behavioral and environmental factors, occurring at individual, family and community levels [15]. Some of these factors (covariates) are not observed or captured in a 
social survey like NDHS which is the dataset that most researchers in Nigeria utilize. Therefore, this study will determine which of infant or child mortality is most affected by unobserved heterogeneity in rural Nigeria.

\section{Methods}

\subsection{Setting}

The population of Nigeria based on 2006 population and housing census was 140,431,790 with an estimated growth rate of 3.2\% per annum [14]. But United Nation population Fund in 2011 put Nigeria population at 167 million which is the sixth largest in the world after Brazil, Indonesia, USA, India and China.

Administratively and politically, Nigeria is divided into six geo-political zones: South- South, South East, South West, North Central, North West, and North East and it is subdivided into 36 states and a Federal Capital Territory. Presently, Nigeria is governed by democratically elected leaders both at national and state levels.

The Nigeria fertility rate has remained high since 2003 with a Total Fertility Rate (TFR) of 5.5 births per woman. The North West Zone has the highest TFR of 6.7 while the lowest is the South -South Zone with TFR of 4.3 births per woman. Also, the rural areas have higher TFR than the urban areas (6.2 versus 4.7) [14].

\subsection{Data Sources}

This study involved secondary analysis of nationally representative data from the 2013 Nigerian Demographic and Health Survey. The 2013 NDHS used the sampling frame for the Nigerian 2006 National Population and Housing Census. The survey covered all the 36 states and the Federal Capital Territory, Abuja. Information on deaths and births of children aged less than five years was obtained from 23403 eligible rural women, aged 15-49 years who were either permanent residents in the selected households or visitors that slept in the selected households on the night preceding the survey. From these women, a total (weighted) of 20702 live-born infants were obtained. The analyses were restricted to live births and most recent births during the five years preceding the surveys to limit mothers' potential for differential recall of events, as deliveries had occurred at different points in time prior to the interview. For detailed sampling procedures of 2013 NDHS contact [14].

\subsection{Variables Measurement}

The outcome variables in this study are the risk of infant death and the risk of child death. The risk of death in infancy or childhood is measured as the duration of survival since birth (in months). Independent Variables: these are bio-demographic variables (Sex of the Child, Maternal age at birth of the child, Type of marriage of respondent, Birth interval, Child year of birth, and Maternal age at first birth) and socio-economic variables (Maternal education, Socioeconomic status, Type of toilet facility, Source of drinking water, Marital status of respondents, Religion and Region).

\subsection{Statistical Analysis}

Analyses were done using Stata statistical package (version 12). In this study, univariate analysis was used to present the percentage distribution of the respondents according to the selected variables. And Frailty model was employed to identify which of infant/child mortality is mostly affected by unobserved heterogeneity in rural Nigeria. Also, design weights were calculated to account for the complex nature of sample design of NDHS data.

In all there are two models, for both infant and child mortality. The models are classified as follows:

Model 1 - This is frailty model of the selected socioeconomic variables and outcome variable

Model 2 - This is frailty model of the combination of selected socioeconomic and bio-demographic variables and outcome variable.

The hazard ratios, p-value $<0.05$ and confidence intervals were used to measure the significant effect of unobserved variables on infant and child mortality in rural Nigeria.

The various survival models are based on the distribution that the timing function is assumed to follow [16]. In this study we will utilize the Weibull frailty model. This model is chosen because it is suitable to model hazards that are either increasing or decreasing monotonically [17]. Mortality in human population follow Weibull, because it is generally high in the first years of life, it declines in other ages of childhood, then increasing slowly in adult ages to old age [17]. Based on this point, many researches on childhood mortality used Weibull model [9,11].

The frailty $\alpha$ being an unobserved multiplicative effect on the hazard function which is assumed to follow gamma distribution $g(\alpha)$ with $\alpha>0$ and the mean of $g(\alpha)$ equal to 1. The variance of $g(\alpha)$ is a parameter $\theta$ (theta) that is usually estimated from the data. The model assumes that the individual risk of death is a function of measured (covariates) factors. The model is of the form:

$$
h_{i j}\left(t / x_{i j}, \alpha_{j}\right)=\alpha_{j} h_{i j}\left(t / x_{i j}\right) \text {. }
$$

The indices $\mathrm{i}$ and $\mathrm{j}$ correspond to observations in children and mothers, respectively. If the variance estimate $\theta$ is different from zero it indicates that unobserved and unmeasurable family factors affect the risk of death hence their survival risks are correlated. And if the variance estimate $\theta$ is zero, then, all families have the same risk of death. Also, individuals with frailty $\alpha>1$ have a higher hazard and decreased chance of survival compared to those with frailty $\alpha=1$. And individuals with frailty $\alpha<1$ have a decreased hazard and higher chance of survival compared to those with frailty $\alpha=1$ [18].

Further, at the multivariate level, analyses were run separately for infant mortality and for child mortality, to examine the effect of some selected covariates on infant and child mortality and to find out how unobserved heterogeneity affect survival chance in infancy and childhood. 


\section{Results}

Table 1 shows the distribution of selected socioeconomic and bio-demographic variables based on the 2013 NDHS data.

Table 2 presents the result from the fitted hazard models for infant and child mortality. From the table a total of 1,382 children died in infancy and a total of 677 children died between 12 and 59 months. For all the models, the chi-squared statistics and log likelihood ratios describing the model goodness of fit are all significant.

The estimated variance parameters associated with the frailty effect, $\theta$, in the Weibull frailty model in infant mortality are 0.507 and 0.518 in Model I and Model II, respectively.

The estimate in model II implies that one infant death in a family is related to about 51 percent increase in the risk of the index infant dying comparative to what it would have been assuming the infant were alive.

The Weibull frailties in child mortality are 0.602 and 0.565 in Model I and Model II respectively. These parameters are very significant and the standard errors (not included) associated with the hazard ratios of the variables are constantly higher, which in turn result to wider confidence intervals.

\section{Effects of Unobserved heterogeneity on Infant and} Child mortality

This indicated that the increase is generally small and does not alter the significance of any of the parameter estimates.

The results show that all the biodemographic and socioeconomic variables, after controlling for each other, are significantly related to child survival. Like in infant mortality, these estimates are significant and show that the risks of child death between families keep on differing even after controlling for a number of observed determinants of childhood mortality.

The estimate in model II imply that one child death in a family is related to about 57 percent increase in the risk of the index child dying comparative to what it would have being assuming the child were alive. These results imply that, in contrast to infant mortality, there is huge difference between families in the risk of child mortality that is not accounted for by the measured and observed factors.
Table 1. Percentage distribution according to selected factors

\begin{tabular}{|c|c|c|}
\hline Variables & Frequency & Percentage \\
\hline \multicolumn{3}{|l|}{ Sex of the child } \\
\hline Male & 10431 & 50.4 \\
\hline Female & 10271 & 49.6 \\
\hline \multicolumn{3}{|l|}{ Type of marriage } \\
\hline Monogamous & 11635 & 56.2 \\
\hline Polygamous & 9067 & 43.8 \\
\hline \multicolumn{3}{|c|}{ Maternal age at child birth } \\
\hline$<20$ years & 3719 & 18.0 \\
\hline 20-35 years & 13887 & 67.1 \\
\hline$>35$ years & 2427 & 11.7 \\
\hline \multicolumn{3}{|l|}{ Birth interval } \\
\hline First birth & 3776 & 18.2 \\
\hline$<24$ months & 3963 & 19.1 \\
\hline 24-35 months & 6775 & 32.7 \\
\hline$>35$ months & 6188 & 29.9 \\
\hline \multicolumn{3}{|c|}{ Maternal age at first birth } \\
\hline$<20$ years & 11097 & 53.6 \\
\hline 20-35years & 7172 & 34.6 \\
\hline$>$ 35years & 48 & 0.2 \\
\hline \multicolumn{3}{|l|}{ Child year of birth } \\
\hline $2012-2013$ & 5347 & 25.8 \\
\hline 2010-2011 & 7225 & 34.9 \\
\hline 2008-2009 & 5746 & 27.8 \\
\hline \multicolumn{3}{|l|}{ Maternal education } \\
\hline None & 13144 & 63.5 \\
\hline Primary & 3763 & 18.2 \\
\hline Secondary and higher & 3790 & 18.3 \\
\hline \multicolumn{3}{|l|}{ Socioeconomic status } \\
\hline Poor & 8972 & 43.3 \\
\hline Middle & 3555 & 17.2 \\
\hline Rich & 5790 & 28.0 \\
\hline \multicolumn{3}{|l|}{ Marital status } \\
\hline Never married & 2796 & 13.5 \\
\hline Married & 17906 & 86.5 \\
\hline \multicolumn{3}{|l|}{ Religion } \\
\hline Catholic & 1814 & 8.8 \\
\hline Other Christian & 6199 & 29.9 \\
\hline Islam & 10026 & 48.4 \\
\hline Others & 199 & 1.0 \\
\hline \multicolumn{3}{|c|}{ Source of drinking water } \\
\hline Unimproved & 11215 & 54.2 \\
\hline Improved & 9487 & 45.8 \\
\hline \multicolumn{3}{|l|}{ Type of toilet facilities } \\
\hline Unimproved & 13050 & 63.0 \\
\hline Improved & 7652 & 37.0 \\
\hline \multicolumn{3}{|l|}{ Region } \\
\hline North-west & 9125 & 44.1 \\
\hline North-east & 4213 & 20.4 \\
\hline North-central & 3368 & 16.3 \\
\hline South-east & 860 & 4.2 \\
\hline South-south & 1908 & 9.2 \\
\hline South-west & 1228 & 5.9 \\
\hline
\end{tabular}

Table 2. Hazard ratios of Infant and Child mortality associated with selected factors

\begin{tabular}{|c|c|c|c|c|}
\hline \multirow{2}{*}{ Variables } & \multicolumn{2}{|c|}{ Frailty model for Infant Mortality } & \multicolumn{2}{|c|}{ Frailty model for Child Mortality } \\
\hline & Model I & Model II & Model I & Model II \\
\hline \multicolumn{5}{|c|}{ Sex of the child } \\
\hline Male & 1.00 & 1.00 & 1.00 & 1.00 \\
\hline Female & $0.75(0.64,0.89)^{*}$ & $0.75(0.63,0.89)^{*}$ & $0.82(0.65,1.03)$ & $0.83(0.66,1.05)$ \\
\hline \multicolumn{5}{|c|}{ Type of marriage } \\
\hline Monogamous & 1.00 & 1.00 & 1.00 & 1.00 \\
\hline Polygamous & $1.02(0.85,1.22)$ & $1.06(0.88,1.28)$ & $1.08(0.84,1.37)$ & $1.09(0.84,1.42)$ \\
\hline \multicolumn{5}{|c|}{ Maternal age at child birth } \\
\hline$<20$ years & 1.00 & 1.00 & 1.00 & 1.00 \\
\hline 20-35 years & $1.01(0.78,1.32)$ & $1.07(0.81,1.40)$ & $0.88(0.61,1.26)$ & $1.06(0.73,1.54)$ \\
\hline$>35$ years & $1.63(1.16,2.30)^{*}$ & $1.67(1.18,2.38)^{*}$ & $1.32(0.83,2.10)$ & $1.44(0.90,2.31)$ \\
\hline \multicolumn{5}{|l|}{ Birth interval } \\
\hline First birth & 1.00 & 1.00 & 1.00 & 1.00 \\
\hline$<24$ months & $1.20(0.91,1.59)$ & $1.10(0.83,1.47)$ & $1.57(1.05,2.36)^{*}$ & $1.22(0.81,1.86)$ \\
\hline 24-35 months & $0.54(0.41,0.71)^{*}$ & $0.50(0.37,0.66)^{*}$ & $1.05(0.71,1.56)$ & $0.83(0.55,1.25)$ \\
\hline$>35$ months & $0.33(0.25,0.45)^{*}$ & $0.31(0.23,0.42)^{*}$ & $0.54(0.35,0.84)^{*}$ & $0.44(0.28,0.70)^{*}$ \\
\hline
\end{tabular}




\begin{tabular}{|c|c|c|c|c|}
\hline \multirow{2}{*}{ Variables } & \multicolumn{2}{|c|}{ Frailty model for Infant Mortality } & \multicolumn{2}{|c|}{ Frailty model for Child Mortality } \\
\hline & Model I & Model II & Model I & Model II \\
\hline \multicolumn{5}{|l|}{ Maternal age at first birth } \\
\hline$<20$ years & 1.00 & 1.00 & 1.00 & 1.00 \\
\hline 20-35years & $1.04(0.87,1.24)$ & $1.03(0.85,1.24)$ & $1.04(0.82,1.32)$ & $1.03(0.80,1.33)$ \\
\hline >35years & $4.19(1.15,15.21)^{*}$ & $4.45(1.23,16.11)^{*}$ & $0.49(0.03,8.95)$ & $0.45(0.02,9.02)$ \\
\hline \multicolumn{5}{|l|}{ Child year of birth } \\
\hline 2012-2013 & 1.00 & 1.00 & 1.00 & 1.00 \\
\hline 2010-2011 & $1.20(0.97,1.47)$ & $1.19(0.97,1.47)$ & $1.14(0.86,1.52)$ & $1.16(0.88,1.54)$ \\
\hline 2008-2009 & $1.15(0.93,1.44)$ & $1.14(0.91,1.47)$ & $0.86(0.64,1.17)$ & $0.85(0.63,1.15)$ \\
\hline \multicolumn{5}{|l|}{ Maternal education } \\
\hline None & & 1.00 & & 1.00 \\
\hline Primary & & $1.08(0.85,1.38)$ & & $0.78(0.56,1.11)$ \\
\hline Secondary and higher & & $0.88(0.65,1.19)$ & & $0.32(0.19,0.52)^{*}$ \\
\hline \multicolumn{5}{|l|}{ Socioeconomic status } \\
\hline Poor & & 1.00 & & 1.00 \\
\hline Middle & & $0.93(0.73,1.18)$ & & $0.93(0.67,1.30)$ \\
\hline Rich & & $0.88(0.70,1.10)$ & & $1.10(0.81,1.49)$ \\
\hline \multicolumn{5}{|l|}{ Marital status } \\
\hline Never married & & 1.00 & & 1.00 \\
\hline Married & & $1.25(0.68,2.31)$ & & $0.93(0.41,2.07)$ \\
\hline \multicolumn{5}{|l|}{ Religion } \\
\hline Catholic & & 1.00 & & 1.00 \\
\hline Other Christian & & $1.46(1.04,2.03) *$ & & $1.21(0.79,1.86)$ \\
\hline Islam & & $1.34(0.80,1.61)$ & & $1.14(0.72,1.81)$ \\
\hline Other religion & & $1.28(0.54,3.01)$ & & $4.12(1.47,11.48)^{*}$ \\
\hline \multicolumn{5}{|l|}{ Source of water } \\
\hline Unimproved & & 1.00 & & 1.00 \\
\hline Improved & & $1.04(0.88,1.26)$ & & $0.92(0.72,1.18)$ \\
\hline \multicolumn{5}{|l|}{ Type of toilet facilities } \\
\hline Unimproved & & 1.00 & & 1.00 \\
\hline Improved & & $0.76(0.63,0.91) *$ & & $0.95(0.74,1.21)$ \\
\hline \multicolumn{5}{|l|}{ Region } \\
\hline North-central & & 1.00 & & 1.00 \\
\hline North-east & & $1.42(1.07,1.90) *$ & & $2.06(1.36,3.13)^{*}$ \\
\hline North-west & & $1.64(1.23,2.18) *$ & & $2.41(1.59,3.66)^{*}$ \\
\hline South-east & & $1.40(0.88,2.24)$ & & $1.89(0.90,3.96)$ \\
\hline South-south & & $1.07(0.71,1.63)$ & & $1.47(0.76,2.82)$ \\
\hline South-west & & $1.05(0.70,1.56)$ & & $1.37(0.67,1.24)$ \\
\hline Sample size & 18697 & 18605 & 18697 & 18605 \\
\hline Number of failures & 1382 & 1369 & 1382 & 1369 \\
\hline Negative log likelihood & 7139 & 7061 & 7224 & 7143 \\
\hline Likelihood ratio chi-square & 150 & 184 & 157 & 197 \\
\hline Degree of freedom & 11 & 25 & 11 & 25 \\
\hline Theta & $0.507(0.36,0.71)$ & $0.518(0.36,0.73)$ & $0.602(0.39,0.92)$ & $0.565(0.35,0.90)$ \\
\hline Likelihood ratio chi-square of theta $=0$ & 170.54 & 163.07 & 117 & 106 \\
\hline
\end{tabular}

* significant at $\mathrm{p}<0.05$.

\section{Discussion}

The purpose of this study was to determine which of infant or child mortality is more affected by unobserved heterogeneity in rural Nigeria.

It had been shown from result that infant and child mortality vary due to the measured socioeconomic, and biodemographic factors even though the relationships between the covariates and mortality were often not statistically significant. In this section we discuss the findings on frailty models. Frailty, in the infant and child mortality models, represents a child's vulnerability to the risk of death. It captures the total effect of all factors that influence the child's risk of death that are not included in the baseline hazards presented in the model [19].

The frailty effects presented in frailty model represent unmeasured effects on infant and child mortality. In this study, almost all biodemographic variables are significantly related to infant while most socioeconomic variables are significantly related to child mortality in the frailty model. We observed that the risk of infant mortality is about 5 times more likely for children of mother greater 35 years old at their first birth compared with children of whose their mother's age as at the time of their first birth was less than 20 years. This is in consistent with the study in Kenya by Omariba [9]. This high effect of maternal age at first birth to infant mortality may be due to physiological and sociopsychological factors. The reproductive systems of older mothers are depleted compared to younger mothers [20] and depression associated with late child delivery is also related to infant mortality [21,22].

It was established from the study that there is marginal difference between the effect of frailty for both infant and child mortality. The frailty effects at the family level for infant and child mortality were 51.8 and 56.5 percent, respectively. The frailty effects were statistically significant. 
This implies that the risks of infant and child deaths between families differ significantly even after controlling for a number of known determinants of infant and child mortality in rural Nigeria. It further implies that the variables in the infant and child mortality model explained 48.2 and 43.5 percent of the family variation in infant and child deaths. Though, the variation was more in infant mortality than child mortality. These results, was in agreement with previous findings. [9,15,22]

The fact that the risk of childhood death is not totally captured by NDHS makes frailty model more interesting and points to unobserved/unmeasured factors. The exclusion of important variables like healthcare, breastfeeding and HIV/AIDS increased the level of the frailty effect, as these are known determinants of child mortality [22].

\section{Conclusions}

The findings revealed that the bio-demographic variables account more for mortality during the infant age (0-11 months) while socioeconomic variables account more for mortality during the childhood age (12-59 months) in rural Nigeria.

Also, family frailty for both infant and child mortality is 51.8 and 56.5 percents respectively in rural Nigeria. The magnitude of the unexplained variation in infant and child mortality by the measured covariates represents infant and child vulnerability to the risk of death. Therefore, child mortality is more affected by unobserved heterogeneity than infant mortality in rural Nigeria even though the difference is minimal.

\section{References}

[1] Mutunga, C. J. Environmental Determinants of Child Mortality in Kenya. UNU-WIDER Research paper No. 2007/83. Helsinki: United Nations University World Institute for Development Economics Research. 2007

[2] UNICEF. Levels and Trends on child mortality report. 2013.

[3] Cai, L. C. Rural-Urban Differentials of Premature Mortality Burden in South-West China International Journal for Equity in Health. 2006; 5: 13-18.

[4] Ellen, V. D. P., Owen O. and Eddy, V. D. What Explains the Rural-Urban Gap in Infant Mortality: Household or Community Characteristics? Demography. 2009; 46(4): 827-850.

[5] Anyamele, O.D. Urban and rural differences across countries in child mortality in sub-Saharan Africa. Journal of Health Care Poor Underserved. 2009; 20(4), 90-98.
[6] Abimbola O. A. Differential Pattern in Child Mortality Rate in Rural Nigeria. Annual Research \& Review in Biology. 2015; 7(5): 309-317.

[7] Antai, D. Regional inequalities in under-5 mortality in Nigeria: a population-based analysis of individual- and community-level determinants. Population Health Metrics. 2011; 9(6): 1-27.

[8] Odimegwu, C. O. Determinants of Breast-Feeding Status in Eastern Nigeria. Journal of African Population Studies. 2002; 17(1): 69-82.

[9] Omariba, D. W. Determinants of infant and child mortality in Kenya: an analysis controlling for frailty effects. Popul Res Policy Rev 2007; 26(3): 299-321.

[10] Damodar, S., Saritha, N., Lucky, S., Gulati, B. K. and Arvind, P. Levels, trends \& predictors of infant \& child mortality among Scheduled Tribes in rural India. Indian J Med Res. 2015; 141: 709-719.

[11] Wegbom A.I., Wokoma D.S.A., Nnoka L.C. and Onyesom O,. What explains the high rate of Infant mortality in rural Nigeria: Biodemographic or Socioeconomic factors? Int'l Journal of Health Sciences and Research. 2016; 6(8): 317-323.

[12] Akinyemi J.O., Bamgboye E.A. and Ayeni O., New trends in under-five mortality determinants and their effects on child survival in Nigeria: A review of childhood mortality data from 1990-2008. African Population Studies, 2013. 27 (1):25-42

[13] Sastry, N. What explains rural-urban differentials in child mortality in Brazil? Social science \& medicine. 1997; 44(7): 989-1002

[14] National Population Commission and ICF Macro. Nigeria Demographic and Health Survey 2013 Report Abuja, Nigeria. 2014.

[15] Niragire, F., Wangombe, A. and Achia, T. N. O. Use of the shared frailty model to identify the determinants of child mortality in Rwanda. Rwanda Journal of Mathematical Sciences, Engineering and Technology. 2011; 20: 89-105..

[16] Cleves, M. A., Gould, W. W. and Gutierrez, R. G. An introduction to survival analysis using Stata. College Station, TX: Stata Corporation. 2004.

[17] Blossfeld, H.-P., \& Rowher, G. Techniques of event history modelling: New approaches to causal analysis. London, England: Lawrence Erlbaum Associates. 2002.

[18] Kleinbaum, D. and Mitchel, K. Survival Analysis: A SelfLearning Text. $2^{\text {nd }}$ ed. Springer Science + Business Media, Inc. 2005.

[19] Govert, E. B. Multistate event history analysis with frailty. Journal of population sciences. 2014; 30(58): 1591-1620

[20] Adeboye, M. A., Ojuawo, A, Ernest, S. K., Fadeyi, A. and Salisu, O. T. Mortality pattern within twenty-four hours of emergency paediatric admission in a resource-poor nation health facility. West African Journal of Medicine. 2010; 29(4): 249-252.

[21] John L. O. Maternal Age at First Birth and Childhood Mortality in Yoruba Society: The Case of Osun State, Nigeria. Research on Humanities and Social Sciences. 2013.

[22] Justine, B. N., Henry, G. M, and Thomas N. O. A. Understanding the determinants of underfive mortality in Uganda including the estimation of unobserved household and community effects using both frequentist and Bayesian survival analysis approaches. BMC Public Health. 2015; 15:1003. 